\title{
The distribution of lagomorph syphilis caused by Treponema paraluisleporidarum in Europe
}

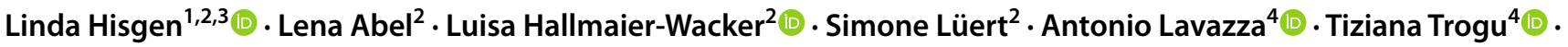

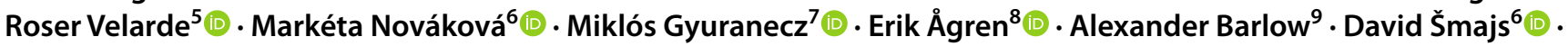 \\ Sascha Knauf ${ }^{1,2,3}$ (1)
}

Received: 15 December 2020 / Revised: 22 September 2021 / Accepted: 23 September 2021 / Published online: 1 October 2021

(c) The Author(s) 2021

\begin{abstract}
Treponema paraluisleporidarum infects both rabbits (ecovar Cuniculus) and hares (ecovar Lepus). While the occurrence of the bacterium has previously been reported for European brown hares (Lepus europaeus) and domestic rabbits (Oryctolagus cuniculus f. domestica), there are no data available that report infection in the European context. We tested a total of 1,995 serum samples and 287 genital swabs from opportunistically sampled European brown hares (Lepus europaeus; $n=2135$ ), Mountain hares (Lepus timidus; $n=4$ ), European rabbits (Oryctolagus cuniculus; $n=138$ ), and pet rabbits $(O$. cuniculus $f$. domestica; $n=5$ ). The samples originated from eight European countries. In case only serum was available, we tested the samples for the presence of anti-treponemal antibodies. For this, we utilized the Treponema pallidum-particle agglutination test (TP-PA), which is suited for the use in lagomorphs due to the antigenic cross-reactivity of anti-T. pallidum and antiT. paraluisleporidarum antibodies. In addition, the results of 380 sera were confirmed using the fluorescent-Treponema antibody absorption test (FTA-ABS). In all cases where swab samples were available, DNA was extracted and tested using quantitative PCR to test for the presence of the lagomorph syphilis-bacterium. We were able to detect antibodies in 825 of 1,995 lagomorph sera (41.4\%; brown hare: 825/1,868; rabbit: 0/127) and obtained positive qPCR results from 182 of 287 swab samples (63.4\%; European brown hare: 167/267; mountain hare: 4/4; rabbit: 11/16). While all rabbit sera $(n=127)$ tested negative for anti-treponemal antibodies, the presence of the bacterium was confirmed in eight wild $(n=8 / 11)$ and three domestic rabbits $(n=3 / 5)$ from Germany using qPCR.
\end{abstract}

Keywords Epidemiology $\cdot$ European brown hare $\cdot$ Rabbit $\cdot$ Mountain hare $\cdot$ Serology $\cdot$ Sexually transmitted disease

\section{Introduction}

Treponema paraluisleporidarum, formerly known as $T$. paraluiscuniculi, is the causative agent of syphilis infection in lagomorphs. Known host species are the European

Sascha Knauf

sascha.knauf@fli.de

1 Department for Animal Science, Georg-August University, Goettingen, Germany

2 Infection Biology Unit, Deutsches Primatenzentrum GmbH, Goettingen, Germany

3 Institute of International Animal Health/One Health, Friedrich Loeffler Institute, Federal Institute for Animal Health, Suedufer 10, 17493 Greifswald-Island Riems, Germany

4 Istituto Zooprofilattico Sperimentale della Lombardia e dell'Emilia Romagna, Brescia, Italy brown hare (EBH, Lepus europaeus) (Horvath et al. 1979), the mountain hare (Lepus timidus) (Mörner 1999), and the European rabbit (Oryctolagus cuniculus) (CunliffeBeamer and Fox 1981). The lagomorph-infecting pathogen is a close relative to the human syphilis bacterium

5 Departament de Medicina I Cirurgia Animals, Universitat Autònoma de Barcelona, Bellaterra, Spain

6 Department of Biology, Faculty of Medicine, Masaryk University, Brno, Czech Republic

7 Institute for Veterinary Medical Research, Hungarian Academy of Science, Budapest, Hungary

8 Swedish National Veterinary Institute, Uppsala, Sweden

9 Wildlife Network for Disease Surveillance, Bristol Veterinary School, Langford, UK 
Treponema pallidum (whole genome similarity $98.1 \%$ to strain Nichols) (Strouhal et al. 2007; Šmajs et al. 2011, 2018). Based on the low number of observed genetic differences, Lumeij et al. (2013) suggested an ecovar status for the rabbit (ecovar Cuniculus $(T P \mathrm{eC})$ ) and hare-infecting (ecovar Lepus $(T P \mathrm{eL})$ ) strains of $T$. paraluisleporidarum. In a cross-infection study, they were able to show that $T P \mathrm{eC}$ caused seroconversion in EBHs but it did not lead to clinical manifestations. Contrary to this, infection with TPeL caused skin ulceration in both rabbits and hares (Lumeij et al. 2013). Lagomorph syphilis is considered apathogenic to humans due to genome decay with deletions mainly found in the tpr gene family (Šmajs et al. 2011), a group of genes that is considered to be important for treponemal pathogenicity and host specificity (Centurion-Lara et al. 2013). However, our current knowledge is based on a single wholegenome of a rabbit-infecting strain Cuniculi A (GenBank accession no.: NC_015714.1). Since the genetic diversity of lagomorph-infecting treponemes has not yet been investigated, it is open to speculation if all lagomorph-infecting strains show similar genome decay and whether $T P \mathrm{eC}$ and $T P$ eL naturally infect both rabbits and hares. To answer these questions, we considered it necessary to review and investigate the distribution of treponematosis in European lagomorphs and find evidence of naturally occurring $T P \mathrm{eC}$ infection in wild European rabbits.

\section{Material and methods}

We collected a total of 1,995 serum samples and 287 genital swab samples from eight European countries (Table S1, online resource). Samples originated from legally hunted animals (Hungary, Germany, Netherlands, Sweden, Italy), carcasses (Spain, Great Britain), or live-trapping in restocking areas, prior to translocation (Italy). The Czech hare samples originated from live hares on three breeding farms. No animals were purposefully killed for this research.

\section{Serology}

Infection with $T$. paraluisleporidarum induces a lifelong antibody response in lagomorphs (Baker-Zander and Sell 1980). Since antibodies are known to be cross-reactive to $T$. pallidum (TP) antigen (Baker-Zander and Lukehart 1984), we screened serum samples using the T. pallidum-particle agglutination assay (TP-PA; Fujirebio Diagnostics Inc., Malvern, PA, USA). Briefly, gelatin particle carriers sensitized with purified $T P$ antigen (strain Nichols) agglutinate in the presence of cross-binding antibodies. We performed the test according to the manufacturer's instructions. After a 2-h incubation period at room temperature, positive samples showed an agglutination that covered the bottom of the well, whereas negative samples showed a defined button-shaped particle concentrated in the center of the well. TP-PA results of 374 sera and an additional six samples, which were previously not tested, were confirmed using the fluorescent-Treponema antibody absorption assay (FTAABS test, Mast Diagnostica GmbH, Reinfeld, Germany). Here, we incubated serum samples in a preparation containing antigens of Treponema (Reiter-strain) to remove non-specific antibodies. In case anti-treponemal antibodies are present, these bind to the outer membrane proteins of T. pallidum strain Nichols organisms that are plotted to a glass slide. Anti-Treponema antibodies were visualized using a fluorescence microscope (ZEISS LSM 5 Pascal) after the addition of fluorescein isothiocyanate-labelled secondary anti-rabbit immunoglobin G (F9887, SigmaAldrich). A previously collected EBH serum sample that contained anti-treponemal antibodies was included as a positive control. Samples that reacted positive in the TP-PA with unsensitized-particles (USPs) and which were negative in the FTA-ABS assay were pooled in groups of five and underwent a pre-absorption with USP in the TP-PA assay (50 $\mu \mathrm{l}$ of lagomorph serum incubated in $950 \mu \mathrm{l}$ USP for $30 \mathrm{~min}$ at room temperature). Samples were then centrifuged, and the supernatants were retested in the TP-PA assay.

\section{Quantitative PCR}

DNA was extracted from swab material using the QIAamp DNA mini kit (QIAGEN, Hilden, Germany) following the manufacturer's instructions. We measured the DNA yield using a NanoDrop photometer (ThermoFisher Scientific, Darmstadt, Germany) and subsequently performed a quantitative PCR (qPCR) targeting the polymerase I gene (polA). This locus is reported to be specific for $T$. paraluisleporidarum and T. pallidum (Liu et al. 2001). Briefly, a TaqMan ${ }^{\circledR}$ qPCR was performed using newly designed primers S 5'-GCAGGATGTTATGCTTGCACG and AS 5'-TACGTTTAAGTTCTACAGGGTCAGT in combination with the probe 5'FAM-TGCAGGTCATTA TCGTGGTGT-TAMRA. The reaction mix included $10 \mu \mathrm{L}$ TaqMan Universal MasterMix II (no Uracil-N glycosylase; Applied Biosystems) and $1.8 \mu \mathrm{L}$ of each $10 \mu \mathrm{mol} / \mathrm{L}$ primer and probe. The total genomic DNA concentration of the sample added to each reaction was normalized to $100 \mathrm{ng}$. Molecular-grade water was used to adjust the reaction volume to $20 \mu \mathrm{L}$. A dilution series of a plasmid (pCR 4-TOPO vector, Thermo Fisher Scientific) that contained the $71 \mathrm{bp}$ target sequence was used as a reference for quantification. Cycling conditions were as follows: 
$95{ }^{\circ} \mathrm{C}$ for $10 \mathrm{~min}$, followed by 50 cycles each at $95{ }^{\circ} \mathrm{C}$ for $15 \mathrm{~s}$ and $60{ }^{\circ} \mathrm{C}$ for $60 \mathrm{~s}$. Reactions were run on a StepOnePlus RealTime PCR System (Applied Biosystems). We tested all samples in duplicates and analyzed raw data using the StepOne version 2.3 software (Applied Biosystems). Duplicates with a standard deviation greater 0.5 were excluded from further analysis.

\section{Results}

A large number of the tested EBH samples reacted positive for antibodies or allowed amplification of treponemal DNA, respectively (Figs. 1 and 2, Table S1). In the TP-PA test, $785 / 1,862 \mathrm{EBH}(42.2 \%)$ and $0 / 127$ wild rabbit (0\%) samples were distinctly positive for anti-Treponema antibodies. Altogether, 137 serum samples (EBH: $n=107$; wild rabbit: $n=30$ ) showed non-evaluable results in the TP-PA test due to an indistinct reaction and/or a reaction in the control well with unsensitized particles (Fig. 1).

For the FTA-ABS testing we included all sera with non-evaluable results $(n=137)$ as well as an additional 237 randomly selected samples plus six samples that were not previously tested with the TP-PA due to shortage of serum. One hundred seventy-five out of $341 \mathrm{EBH}$ samples
(51.3\%) tested positive in contrast to the rabbit samples, which all tested negative in the FTA test $(n=0 / 39)$. In a single case, a TP-PA-positive sample tested negative in the FTA-ABS test, whereas two TP-PA-negative sera were confirmed positive in the FTA-ABS test. Table S1 summarizes the results and provides further details about the origin of samples. Additionally, we performed a preabsorption of 30/137 non-evaluable serum samples (25 FTA negative (pooled in 5 groups) and five FTA-positive samples) and retested them in the TP-PA test, where they showed no reaction in the control well and distinct results identical to the respective outcome in the FTA-ABS test (Fig. 1).

For qPCR amplification, 182 of 287 genital swab samples (63.4\%; EBH: 167/267; mountain hare: 4/4; wild rabbit: $3 / 5$; domestic rabbit: $8 / 11$ ) showed a clear amplification of the polA gene target (Italy: $5 / 5(100.0 \%)$; Netherlands: 2/2 (100.0\%); Germany: 160/214 (74.8\%); Czech Republic: 4/54 (7.4\%); Great Britain: 7/8 (87.5\%); Sweden: 4/4 (100.0\%), Fig. 2, Table S1). polA copy numbers ranged from three to $10 \mathrm{e} 6$ copies $(7.07 \mathrm{e} 4 \pm 2.20 \mathrm{e} 4$, mean \pm SEM), with mean copy numbers ranging from eight copies in the Czech Republic $(n=4)$ to $8.37 \mathrm{e} 5$ in Sweden $(n=4)$. We note here that sample size and sample quality differed greatly per country.
Fig. 1 Flow chart displaying work process and results by species. The total number of tested samples is given in bold, followed by the quantity per species (EBH: European brown hare). All of the samples with obscure results and/or a reaction with unsensitized particles (USP, control) were tested in the FTA-ABS test (brown frame). A total of 30 samples were preabsorbed and retested in the TP-PA assay

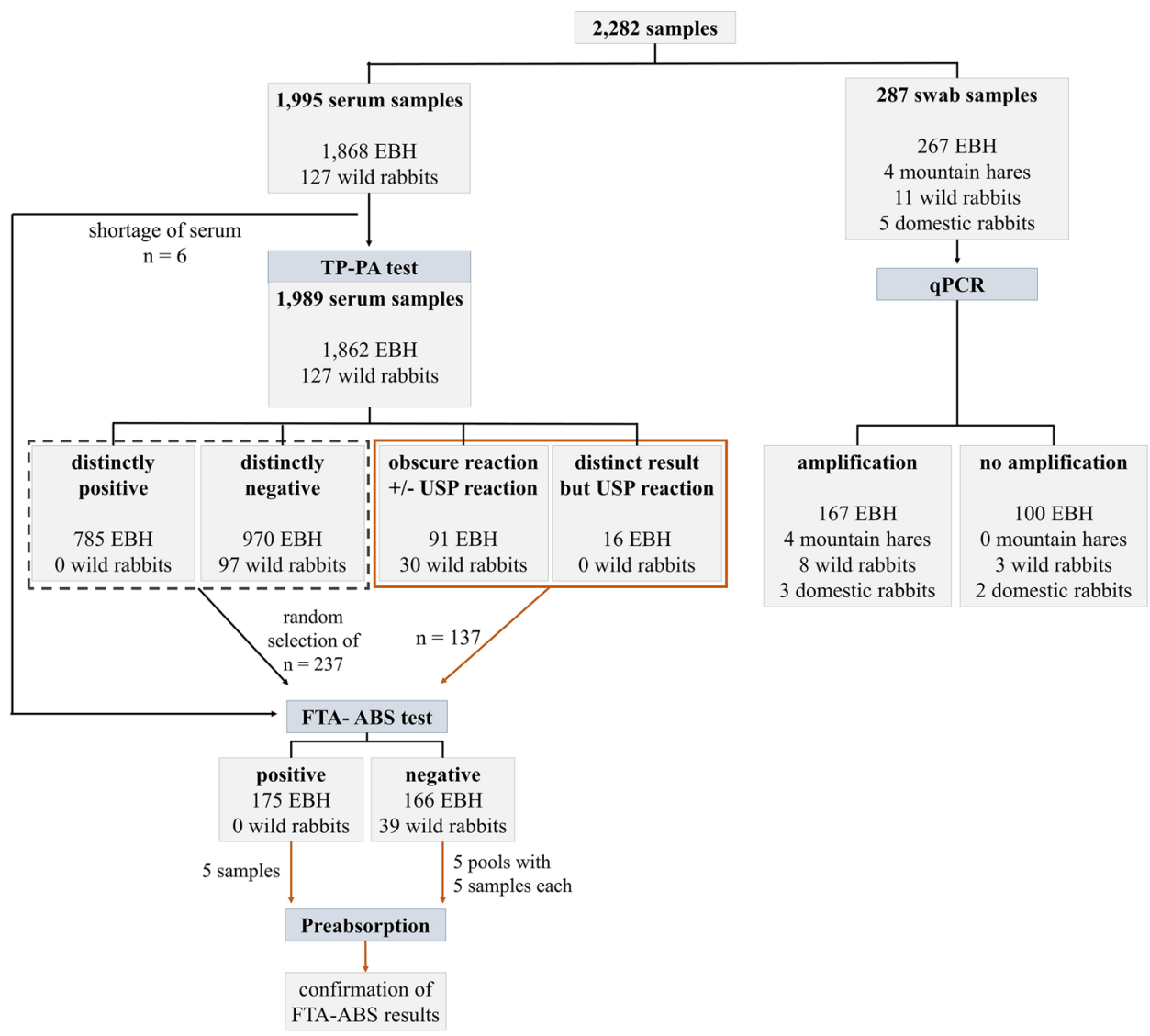




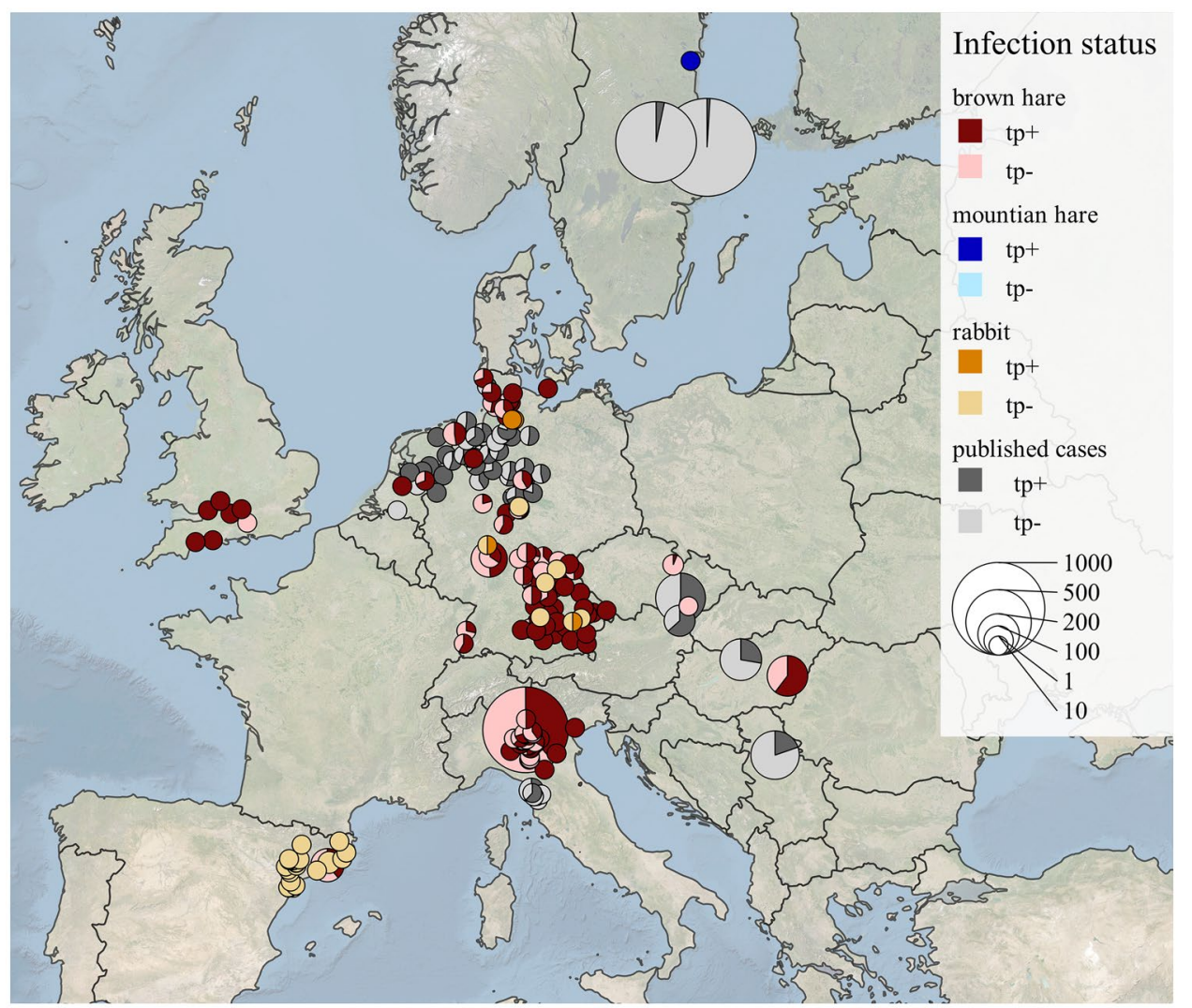

Fig. 2 A map of central Europe showing the origin of the tested lagomorph samples and their Treponema paraluisleporidarum (tp) infection status. Serum samples were tested using the Treponema pallidum particle agglutination assay and the fluorescent treponemal antibody absorption test, while treponemal DNA in swab and tissue samples was demonstrated using qPCR. Grey-colored pie charts present previously reported cases (Jakšić 1957; Horvath et al. 1979; Lumeij et al. 1994; Mörner 1999; Verin et al. 2012; Posautz et al. 2014; Nováková et al. 2019; Hisgen et al. 2020). Colored pie charts show samples that

\section{Discussion}

Different methods were used to confirm infection with $T P \mathrm{eC} / \mathrm{L}$ in our lagomorph sample collection. For this study, we either had serum samples, which did not allow nucleic acid tests or genital swab samples that were of no use for serum-antibody detection. However, despite the differences in sample material and methods, both, serology and qPCR, allow a clear statement on the infection status of the lagomorph host. The first documentation of syphilitic lesions in German EBHs was as early as 1874 (Bollinger 1874) followed by demonstration of spirochetes in hare tissue specimens from Serbia in 1957 (Jakšić 1957). Since then, the occurrence of the bacterium has been described in several hare populations throughout Europe, namely Hungary (Horvath et al. 1979), the Netherlands (Lumeij et al. 1994), Sweden (Mörner 1999), central Italy (Verin et al. 2012), Austria and Germany (Posautz et al. 2014; were subject to this study, different colors indicate different species (red: European brown hare; blue: mountain hare; orange: rabbit). The darker colors represent the proportion of positively tested animals, the brighter colors negatively tested samples. In case no geo-tags were available, we used the coordinates of the sample providing institution. The map was created using QGIS version 3.16.0 (QGIS Geographic Information System. Open-source Geospatial Foundation Project; map source: Esri [https://server.arcgisonline.com/ArcGIS/rest/services/ World_Imagery/MapServer/tile/ $\{\mathrm{z}\} /\{\mathrm{y}\} /\{\mathrm{x}\}])$

Hisgen et al. 2020), and the Czech Republic (Nováková et al. 2019) (Fig. 2, gray circles). These published data are now further complemented by the findings generated in this study (Fig. 2, yellow- and red-colored circles) where 992 of 2,135 EBHs (46.5\%), 4 of 4 mountain hares (100.0\%) and 11 of 143 rabbits $(7.7 \%)$ tested positive for the presence of the syphilis bacterium. Moreover, our results are within the range of previously reported prevalence rates from other European countries, which range from 1.9 (Mörner 1999) to $64.0 \%$ (Posautz et al. 2014).

The close genetic relatedness of $T P \mathrm{eC} / \mathrm{L}$ and $T P$ and the resulting cross-reactivity of antibodies render the serological tests used in this study suitable for the use in lagomorphs (Baker-Zander and Lukehart 1984). The unspecified results in the TP-PA test (121 out of 1989 samples) are likely associated with low sample quality. In hunted lagomorphs, serum samples are often haemolytic or contain clotted blood components. This could explain unusual 
binding patterns that result in false positive, doubtful reactions as well as unspecific cross-linkage of the USP. The latter was circumvented by repeating the TP-PA assay after pre-absorption.

Interestingly, we were not able to detect antibodies in European wild rabbits $(n=127)$, despite the clear evidence of infection in German wild $(n=8 / 11)$ and domestic $(n=3 / 5)$ rabbits based on our qPCR data. Unfortunately, serum and genital swab samples were not paired which prevents us from making any assumption on the seroconversion of $T P \mathrm{eC} / \mathrm{L}$ infected wild rabbits. However, from laboratory rabbits, it is known that $T P$ infection causes a strong antibody response (Alderete and Baseman 1981). Our findings warrant further investigations in particular in areas where hares and rabbits share the same habitat and are supportive for a study conducted in Australia, where equally no antibodies have been detected in wild rabbits (Graves et al. 1980). While the polA targeting qPCR presents a well-established method, polA copy numbers in lagomorphs differed markedly between the samples and across the sampling sites. This is not surprising since various parameters such as sampling technique and sample quality are known to impact copy numbers. Similar results have been reported from non-human primate infection with $T$. pallidum subsp. pertenue (Knauf et al. 2012).

The anthropogenic effect on the distribution and diversity of lagomorph-infecting $T P \mathrm{eC} / \mathrm{L}$ has yet to be investigated. EBHs are native to continental Europe and parts of Asia and have been introduced to Scandinavia, Great Britain, North and South America, Australia, and New Zealand (Thulin et al. 2006; Yalden 1999; Flux 1990; Bonino et al. 2010; Jarman and Stott 2008). The effect of lagomorph translocation as a game species (restocking of hunting areas) or the introduction as an alien species into natural ecosystems (e.g., Australia) on hare treponematosis are interesting research questions. The introduction of EBHs to Great Britain, for example, is believed to have occurred in Roman times or even earlier (Corbet 1986). The presence of Treponema in British hares is, therefore, of particular interest to understand the temporal distribution of $T P \mathrm{eL}$ in Europe, which should trigger further investigations in the UK.

In conclusion, the presence of T. paraluisleporidarum in ten European countries of which two did not report infection previously, argues for a widespread and well-established disease in European lagomorphs (Fig. 2). Further genomic analyses of hare and rabbit-infecting treponemes are on the way, which hopefully provide insight into the diversity and evolution of syphilis in lagomorphs and humans.

Supplementary information The online version contains supplementary material available at https://doi.org/10.1007/s10344-021-01535-w.
Acknowledgements We would like to sincerely thank our contributors for the support of this study: U. Voigt from the Institute for Terrestrial and Aquatic Wildlife Research, University of Veterinary Medicine, Hanover, Germany for providing contact information on local hunters, the hunters, hare breeders and pet rabbit owners who consented to sampling, and the employees of the state agencies for health and food safety in Erlangen, Germany, and Oberschleissheim, Germany, for the sampling of lagomorphs during necropsy. We thank A. Wehrend and K. Wehrend from the Clinic for Veterinary Obstetrics, Gynaecology and Andrology, Giessen, Germany for contributing swab samples. Valter Trocchi contributed greatly to the sample collection from Italian lagomorphs.

Funding Open Access funding enabled and organized by Projekt DEAL. This study was funded by the German Research Foundation (DFG KN1097/7-1 to SK), the Czech Research Foundation (GC18$23521 \mathrm{~J}$ to DŠ), and by the Lendület programme (LP2012/22 to MG) of the Hungarian Academy of Sciences for the samples that originate from Hungary.

Availability of data and material All data generated or analyzed during this study are included in this published article and its supplementary information files.

Code availability Not applicable.

\section{Declarations}

Ethics approval The authors confirm that the ethical policies of the journal, as noted on the journal's author guidelines page, have been adhered to. Ethical clearance was granted by the animal welfare body of the Georg-August-University of Goettingen (Ref. E8/20). Livehandling of hares in Italy was performed by veterinary personnel and took place on behalf of the hunting management bodies as a health surveillance of wild lagomorphs that are designated for restocking. Sampling was therefore not conducted for the purpose of this study. Hares from Germany, Hungary, Sweden, UK, the Netherlands, and Spain originated from carcasses or legally hunted hares; thus, ethical approval was not required. No hares were purposely shot for this study. Authorization for sample import from Spain was granted by the Ministerio para la Transición ecológica (Ref. ESNC25) as required by the Nagoya protocol.

Consent to participate Not applicable.

Consent for publication Not applicable.

Conflict of interest The authors declare no competing interests.

Open Access This article is licensed under a Creative Commons Attribution 4.0 International License, which permits use, sharing, adaptation, distribution and reproduction in any medium or format, as long as you give appropriate credit to the original author(s) and the source, provide a link to the Creative Commons licence, and indicate if changes were made. The images or other third party material in this article are included in the article's Creative Commons licence, unless indicated otherwise in a credit line to the material. If material is not included in the article's Creative Commons licence and your intended use is not permitted by statutory regulation or exceeds the permitted use, you will need to obtain permission directly from the copyright holder. To view a copy of this licence, visit http://creativecommons.org/licenses/by/4.0/. 


\section{References}

Alderete JF, Baseman JB (1981) Analysis of serum IgG against Treponema pallidum protein antigens in experimentally infected rabbits. Br J Vener Dis 57(5):302-308. https://doi.org/10.1136/ sti.57.5.302

Baker-Zander SA, Lukehart SA (1984) Antigenic cross-reactivity between Treponema pallidum and other pathogenic members of the family Spirochaetaceae. Infect Immun 46(1):116-121. https:// doi.org/10.1128/IAI.46.1.116-121.1984

Baker-Zander S, Sell S (1980) A histopathologic and immunologic study of the course of syphilis in the experimentally infected rabbit. Demonstration of long-lasting cellular immunity. Am J Pathol 101(2):387-414

Bollinger O (1874) Die Syphilis Der Feldhasen Virchows Archiv 59:349-364

Bonino N, Cossíos D, Menegheti J (2010) Dispersal of the European hare, Lepus europaeus in South America. Folia Zoologica 59(1):9-15. https://doi.org/10.25225/fozo.v59.i1.a3.2010

Centurion-Lara A, Giacani L, Godornes C, Molini BJ, Reid TB, Lukehart SA (2013) Fine analysis of genetic diversity of the $t p r$ gene family among treponemal species, subspecies and strains. Plos Neglect Trop D 7:e2222. https://doi.org/10.1371/journal. pntd.0002222

Corbet GB (1986) Relationships and origins of the European lagomorphs. Mammal Rev 16:105-110

Cunliffe-Beamer TL, Fox RR (1981) Venereal spirochetosis of rabbits: description and diagnosis. Lab Anim Sci 31(4):366-371

Flux JEC (1990) Brown hare. In: King CM (ed) The Handbook of New Zealand Mammals. Oxford University Press, Auckland, New Zealand, pp 161-172

Graves SR, Edmonds JW, Shepherd RC (1980) Lack of serological evidence for venereal spirochaetosis in wild Victorian rabbits and the susceptibility of laboratory rabbits to Treponema paraluiscuniculi. Br J Vener Dis 56(6):381-386

Hisgen L, Abel L, Hallmaier-Wacker LK, Lüert S, Siebert U, Fähndrich M, Strauss E, Voigt U, Nováková M, Šmajs D, Knauf S (2020) High syphilis seropositivity in European brown hares (Lepus europaeus), Lower Saxony. Germany Transbound Emerg Dis 67(5):2240-2244. https://doi.org/10.1111/tbed.13551

Horvath I, Kemenes F, Molnar L (1979) Isolation of pathogenic treponemes from hare. Experientia 35(3):320-321

Jakšić B (1957) Brucellose et syphilis du lievre. Veterinarsky Glasnik 4:423-428

Jarman P, Stott P (2008) Brown hare Lepus europaeus. In: van Dyke S, Strahan R (eds) Mammals of Australia. Reed New Holland, Sydney, Australia, pp 706-707

Knauf S, Batamuzi EK, Mlengeya T, Kilewo M, Lejora IA, Nordhoff M, Ehlers B, Harper KN, Fyumagwa R, Hoare R, Failing K, Wehrend A, Kaup FJ, Leendertz FH, Mätz-Rensing K (2012) Treponema infection associated with genital ulceration in wild baboons. Vet Pathol 49(2):292-303. https://doi.org/10.1177/0300985811402839

Liu H, Rodes B, Chen CY, Steiner B (2001) New tests for syphilis: rational design of a PCR method for detection of Treponema pallidum in clinical specimens using unique regions of the DNA polymerase I gene. J Clin Microbiol 39(5):1941-1946. https://doi. org/10.1128/jcm.39.5.1941-1946.2001

Lumeij JT, de Koning J, Bosma RB, van der Sluis JJ, Schellekens JF (1994) Treponemal infections in hares in The Netherlands. J Clin Microbiol 32(2):543-546. https://doi.org/10.1128/JCM.32.2. 543-546.1994

Lumeij JT, Mikalova L, Šmajs D (2013) Is there a difference between hare syphilis and rabbit syphilis? Cross infection experiments between rabbits and hares. Vet Microbiol 164(1-2):190-194. https://doi.org/10.1016/j.vetmic.2013.02.001

Mörner T (1999) Monitoring diseases in wildlife - a review of diseases in the orders lagomorpha and rodentia in Sweden. Verh Ber Erkrg Zootiere 39:255-262

Nováková M, Najt D, Mikalová L, Kostková M, Vrbová E, Strouhal M, Posautz A, Knauf S, Šmajs D (2019) First report of hare treponematosis seroprevalence of European brown hares (Lepus europaeus) in the Czech Republic: seroprevalence negatively correlates with altitude of sampling areas. BMC Vet Res 15(1):350. https://doi.org/10.1186/s12917-019-2086-3

Posautz A, Leidinger E, Knauer F, Hoffmann D, Suchentrunk F, Walzer C, Kübber-Heiss A (2014) Seroprevalence of Treponema sp. in European brown hares (Lepus europaeus) in Austria and Germany. Wiener Tierärztliche Monatsschrift 101:281-285

Šmajs D, Strouhal M, Knauf S (2018) Genetics of human and animal uncultivable treponemal pathogens. Infect Genet Evol 61:92-107. https://doi.org/10.1016/j.meegid.2018.03.015

Šmajs D, Zobaníková M, Strouhal M, Čejková D, Dugan-Rocha S, Pospíšilová P, Norris SJ, Albert T, Qin X, Hallsworth-Pepin K, Buhay C, Muzny DM, Chen L, Gibbs RA, Weinstock GM (2011) Complete Genome Sequence of Treponema paraluiscuniculi, Strain Cuniculi A: The Loss of Infectivity to Humans Is Associated with Genome Decay. PLoS ONE 6:e20415. https://doi.org/ 10.1371/journal.pone.0020415

Strouhal M, Šmajs D, Matejkova P, Sodergren E, Amin AG, Howell JK, Norris SJ, Weinstock GM (2007) Genome differences between Treponema pallidum subsp. pallidum strain Nichols and T. paraluiscuniculi strain Cuniculi A. Infect Immun 75(12):5859-5866. https://doi.org/10.1128/IAI.00709-07

Thulin CG, Stone J, Tegelström H, Walker CW (2006) Species assignment and hybrid identification among Scandinavian hares Lepus europaeus and L. timidus. Wildlife Biology 12(1):29-38. https:// doi.org/10.2981/0909-6396(2006)12[29:SAAHIA]2.0.CO;2

Verin R, Pestelli M, Poli A (2012) Treponemal infection in free-ranging European brown hares (Lepus europaeus) in central Italy: serology and epidemiology. J Wildl Dis 48(4):1079-1082. https://doi.org/ 10.7589/2011-03-069

Yalden D (1999) The history of British mammals. T \& AD Poyser, London

Publisher's Note Springer Nature remains neutral with regard to jurisdictional claims in published maps and institutional affiliations. 